\title{
Dominique Caubet (a cura di), Les mots du bled. Création contemporaine en langues maternelles. Les artistes ont la parole
}

\section{Ilaria Vitali}

\section{(2) OpenEdition \\ Journals}

\section{Edizione digitale}

URL: http://journals.openedition.org/studifrancesi/36781

DOI: $10.4000 /$ studifrancesi.36781

ISSN: 2421-5856

\section{Editore}

Rosenberg \& Sellier

\section{Edizione cartacea}

Data di pubblicazione: 1 juillet 2005

Paginazione: 205-206

ISSN: 0039-2944

\section{Notizia bibliografica digitale}

Ilaria Vitali, «Dominique Caubet (a cura di), Les mots du bled. Création contemporaine en langues maternelles. Les artistes ont la parole», Studi Francesi [Online], 145 (XLIX | I) | 2005, online dal 30 novembre 2015, consultato il 19 avril 2021. URL: http://journals.openedition.org/studifrancesi/36781 ; DOI: https://doi.org/10.4000/studifrancesi.36781

Questo documento è stato generato automaticamente il 19 avril 2021.

\section{cc) $($ ) $\ominus$}

Studi Francesi è distribuita con Licenza Creative Commons Attribuzione - Non commerciale - Non opere derivate 4.0 Internazionale. 


\title{
Dominique Caubet (a cura di), Les mots du bled. Création contemporaine en langues maternelles. Les artistes ont la parole
}

\author{
Ilaria Vitali
}

\section{NOTIZIA}

DOMINIQUE CAUBET (a cura di), Les mots du bled. Création contemporaine en langues maternelles. Les artistes ont la parole, Paris, L'Harmattan, 2004, pp. 237. Entretiens avec: Fellag, Cheb Sahraoui, Allalou, Youssef Fadel, Fadhel Jaïbi, Baâziz, Ben Mohamed, Aziz Chouaki, Gyps, Amazigh Kateb, Omar Sayed, Rachid Taha, Hamma. présentés et édités par Dominique Caubet.

1 «Les trois langues, c'est ma langue ». Una semplice frase, quella dell'umorista Fellag, sembra racchiudere l'essenza di questo singolare studio, che analizza la creazione musicale e letteraria nello spazio della scena franco-magrebina. Le tre lingue in questione, sono il berbero, l'arabo (con la sua diglossia interna tra varianti letterarie e dialettali) e, naturalmente, il francese. Come conoscere e approfondire la conoscenza e l'utilizzo di tali lingue sulla scena artistica francese contemporanea? In che modo il mélange linguistico unisce elementi antichi e innovativi, creando un lessico "excentrique" rispetto a quello esagonale? Per studiare la delicata questione, Dominique Caubet, socio-linguista presso l'Institut National des Langues et Civilisations Orientales (INALCO), ha intervistato i diretti interessati, realizzando un saggio di eccezionale valore che, attraverso l'analisi dettagliata dei percorsi linguistici di vari autori, finisce per diventare indagine a tutto tondo sulla realtà della creazione nell'istmo dell'"entredeux". A rispondere alle sue domande, in una cornice di interviste e incontri, sono tredici artisti della scena franco-magrebina: uomini di teatro, cantanti, poeti e scrittori diversi tra loro, uniti tuttavia dalla particolarità di vivere nella singolare posizione tra 
due culture. Dieci di loro sono di origine algerina - esiliati in Francia per ragioni che è facile immaginare - persone venute dal popolo, che parlano la lingua del popolo, con l'intento di conferirgli un preciso statuto. Se Fadhel Jaïbi (Tunisia) e Omar Sayed o Youssef Fadel (Marocco) si servono mirabilmente del francese mescolandolo all'arabo dialettale, gli algerini contano nel loro patrimonio culturale un'altra lingua, il berbero, di interesse non trascurabile. Il risultato è la creazione di una nuova lingua, in cui si mescolano i giochi di parole, alla ricerca di effetti stilistici innovativi, originali, polifonici, e che non è da considerarsi solo come l'espressione di una banlieue parigina disagiata, ma diviene un autentico linguaggio, che si può sentire a Evry così come nel $5^{\circ}$ arrondissement. Una particolare attenzione viene accordata da Caubet al teatro e alla canzone, in tutte le sue sfumature: dal Ghiwane, al raï, gnawa, protest song, fino al rock, al techno, al rap. Senza dimenticare poesia e umorismo. Un saggio socio-linguistico sulla creazione artistica, letteraria e musicale tra Francia e Maghreb, che si rivolge non solo ad un pubblico di specialisti, ma è dedicato a tutti coloro che vogliono avvicinarsi al tema della migrazione e della mixité. A tutti coloro che amano navigare nell'istmo dell'entre-deux. 